\title{
Current Trends in Electronic Atlas Production
}

Electronic atlases have the potential to add a new dimension to the use of atlas information. An electronic version can contain data and software to produce maps not possible in book form. They can serve as a preliminary stage to Atlas Information Systems and can also form the core of a multimedia system. The ICA commission on national atlases was formed at the 13th International Cartographic Conference in Morelia, Mexico in 1987 to serve as a forum for electronic atlas conception and production. Electronic atlases have been a topic at every commission meeting ever since. The observations presented in this paper are findings from these meetings.

B y "electronic atlas," we understand a new form of atlases. However, it is not intended to replace the traditional printed atlas. Rather, an electronic atlas will add a new dimension to the use of atlas information. The electronic version can contain data and software to produce maps which are not possible in book form. An electronic atlas can also be seen as a preliminary stage to Atlas Information Systems for different applications in national and regional land use planning. The atlas information can also form the core of a multimedia system, with animated time series information. For these reasons, it is important to devote special efforts to explore the idea of electronic atlases and to disseminate atlas information in digital form.

The term "electronic atlas" was created by Eva Siekierska (1983) and further promoted at AutoCarto London in 1986. The term was adopted by the ICA Commission on National and Regional Atlases (CNRA), which was formed at the 13th International Cartographic Conference in Morelia, Mexico in 1987. Electronic atlases have been a topic at every commission meeting ever since.

The first prototype of an electronic atlas was developed in Canada in 1982 and based on a Graphic Work Station. Since then the Electronic Atlas of Canada has evolved and is now based on a SUN computer platform using SUN-View windows with capabilities to be used both for production and presentation of atlas data. One reason for choosing that platform was a requirement to connect to the National Atlas Information Systems databases that were produced with ARC/INFO (Siekierska 1993).

A more popular platform is the IBM compatible DOS machine with data on CD-ROM. This platform holds promise to reach an interactive multimedia stage. A first step on this road was taken by Jack Massey (1987), who produced a software package called SUPERMAP with facilities to distribute and map census data by using an ordinary IBM compatible DOS machine and the new CD-ROM technology. Although many countries expressed interest in SUPERMAP's capabilities, this interest did not lead to widespread use. I think that one main obstacle was the census bureaus' hesitation to distribute census data at low resolutions. Another obstacle was the lack of base maps to be used as background maps for the statistical data.

The DOS platform serves two other electronic atlas products: the wellknown Electronic Atlas of Arkansas (Smith 1987) which initially required an EGA graphics card and only $3 \mathrm{MB}$ of disk space to store the maps and
Bengt Rystedt

Bengt Rystedt is the Head of a Research and Development section at the National Land Survey of Sweden, Gävle, Sweden S-801 82 bengtr@lmv.lm.se

\section{INTRODUCTION}

\author{
MAIN TECHNICAL \\ PLATFORMS
}


HARDWARE AND SOFTWARE

At the ICA National and Regional Atlases Commission meeting, held in Madrid, Spain

from May 18-22, 1992, eight different electronic atlases were
Sweden's national atlas. In Sweden, the DOS platform was considered in a feasibility study conducted in 1986 (Rystedt 1987). The main reason for choosing an ordinary DOS platform was that the target user group was high school and secondary school students. On the other hand, in the Netherlands the Macintosh platform with HYPERCARD dominates (Ormeling and Koop 1990). ${ }^{1}$

At the commission meeting in Visegrád, Hungary, Aranaz (1993) reported that the project team of the National Atlas of Spain is in the final preparation of a pilot electronic atlas project. Two versions will be tested. Version A will be a high capacity videodisc with a touch screen interface. Version B will be made available on diskettes for use on DOS machines.

There is no doubt that both DOS and Macintosh, with data on CDROM, are suitable platforms for electronic atlases. It seems obvious that the direction on both platforms is towards multimedia. Fancy tools are included for public and school use, while more sophisticated graphics are provided to more distinguished users.

At the ICA National and Regional Atlases Commission meeting, held in Madrid, Spain from May 18-22, 1992, eight different electronic atlases were demonstrated. Documentation of the session can be found in the proceedings from this meeting. A summary of the characteristics of the atlases follows.

Atlas of Biskaia presented by Benjamin Sabiron i Herrero, Instituto Geograff́a Aplicada, Spain.

Computer: DOS with EGA Color monitor (VGA or super VGA preferable).

Software: SPSS+STATGRAF and STATWORK; LOTUS 1-2-3, SYMPHONY and EXCEL; DBASE III; WORDSTAR and WORDPERFECT; PAINTBRUSH etc.

Cartography: AUTOCAD 10.0, MAPINFO 4.6, and ERDAS 7.5.

Content: 20 different themes at resolutions of 1:100,000 and 1:200,000.

The National Atlas Information System presented by Olev Koop, Cartography Section, Faculty of Geographical Sciences, University of Utrecht, The Netherlands.

Computer: Apple Macintosh IIx.

Software: HYPERCARD from Apple Computer and ORACLE to link remote data sources.

Concept: Object orientation and Hypermedia.

Content: $9 \mathrm{MB}$ of data from the National Physical Planning Agency.

\footnotetext{
1. Ferjan Ormeling discusses this further in "New Forms, Concepts, and Structures for
} European National Atlases" on pages 12-20 in this issue of Cartographic Perspectives. 
Transport Atlas of The Southern North Sea presented by Olev Koop, Cartography Section, Faculty of Geographical Sciences, University of Utrecht, The Netherlands.

Computer: IBM PC or compatible with EGA or Hercules graphic card.

Software: Display program on a floppy disk.

Content: A cartographic model to make the information concerning water transport in a conventional atlas more readily accessible.

Electronic Atlas of Arkansas presented by Olev Koop, Cartography Section, Faculty of Geographical Sciences, University of Utrecht, The Netherlands.

Computer: IBM PC or compatible with EGA color graphics.

Software: Special program for searching and browsing.

Content: A traditional regional atlas with some 100 static raster maps.

The Multimedia Map of City of Madrid presented by Miguel Angel Bernabé, Department of Topographical Engineering and Cartography, Polytechnic University of Madrid, Spain.

Computer: Macintosh II ci 5/ 80 with 13 " monitor or $\mathrm{fx} 8 / 80$ with 21 " monitor.

Software: HYPERCARD and the MacroMind package, QUICK TIME and QUARKXPRESS.

Content: The growth of Madrid from the foundation of the city by the Moslems in the ninth century until today.

Territorial Evolution of Canada, a Hypermedia Map presented by Eva Siekierska, Geomatics Canada, Ottawa, Canada.

Computer: Macintosh LC or higher with a 13" RGB monitor.

Software: Package produced with MacroMind DIRECTOR.

Content: Animation of the territorial evolution of Canada.
Of the twelve electronic atlas products listed, two out of three are based on DOS/Windows platform and one out of three is based on the Macintosh Platform. 
At the National and Regional Atlases Commission meeting in

Visegrád, Hungary in April, 1993, two other atlases were presented...
GEOSCOPE-Global Change Encyclopedia presented by Réjean Simard and Luc Michaud, Canada Center for Remote Sensing, Ottawa, Canada.

Computer: IBM PC-AT or compatible with VGA and CD-ROM reader.

Software: Developed in the project with possibilities to use the encyclopedia in different modes.

Content: Global coverage of more than fifty parameters from various remote sensing satellites and other maps. The Digital Chart of the World serves as background.

The National Atlas of Canada presented by Eva Siekierska, Geomatics Canada, Ottawa, Canada.

This presentation, "Philosophy Behind a Multimedia Atlas of Canada" focused on the observations that an electronic atlas is a hypertext and the content is displayed in form of text, diagrams, images, and maps. This makes it very close to multimedia. The National Atlas of Canada contains forty-four different themes and is a magnificent database describing the nature and culture of Canada. The presentation assumed that this database will soon be available as an interactive electronic atlas based on multimedia, hypertext, and electronic networks.

At the National and Regional Atlases Commission meeting in Visegrád, Hungary in April, 1993, two other atlases were presented:

Picture Atlas of the World presented by Betty Kotcher, National Geographic Society, Washington D.C., U.S.A.

Computer: IBM PS/2, DOS and VGA, CD-ROM and audioadapter.

Software: IBM's LINKWAY.

Content: Physical, economic, and cultural geography of the world in the form of photos, video clips, statistics, and essays on every country.

The PC-Atlas of Sweden presented by Wolter Arnberg, Department of Geography, University of Stockholm, Sweden.

Computer: PC-DOS with EGA or higher and CD-ROM.

Software: Developed in the project. DBASE with import functions from MAPINFO and ARC/INFO, and export to EXCEL.

Content: Source data in accordance with the book form. 
In the November 1994 issue of the magazine CD-ROM World, I found the following two products:

World Atlas 5.0 reviewed by Carol S. Holzberg.

Computer: PC 386 or higher, DOS and Windows, SVGA and MPC-compatible sound card.

Software: Property of the publisher: The Software Toolworks, Novato CA, U.S.A.

Content: Topographic, statistical, and relief maps; photos and video clips from every country.

$M a p^{\prime} n^{\prime} G o$ advertised by DeLorme Mapping.

Computer: MS-Windows compatible.

Software: Property of DeLorme Mapping with functions for route planning and printing of travel plan maps.

Content: North American road database, and place names; lists of restaurants, hotels, and tourist attractions.

Of the twelve electronic atlas products listed, two out of three are based on DOS/ Windows platform and one out of three is based on the Macintosh Platform. It is also noticeable that many publishers of electronic atlases choose to produce their own software, although this seems to be more common for the DOS platform.

It is well-known that, before the production of a traditional atlas can begin, the atlas format has to be designed. This is, of course, also valid for electronic atlas production. Once the target user group and its needs have been defined, it is necessary to take a closer look at the electronic atlas user. Bakker, et al. (1988) did so by categorizing the electronic atlas users into the following four groups: professional users, educational users, private users, and commercial users.

The objectives, ambitions, and budget are also prerequisites for atlas design and its user interface. If the goal is to create a multimedia and interactive system, the design phase should be comparable to writing a scenario for a movie or play (Monmonier 1992). For that purpose, authoring software is needed. Although my knowledge in this field is limited, I do know of a course in multimedia production techniques at the University of Utrecht that used Macintosh-based HYPERCARD, AUTHORWARE PROFESSIONAL and MacroMind DIRECTOR (Köbben 1993). The lack of authoring tools for PCs has given some developers the opportunity to write one. ${ }^{2}$

The most important choice an electronic publisher has to make is between a DOS/WINDOWS, Macintosh, or UNIX platform. The ambition

ELECTRONIC ATLAS PRODUCTION TOOLS

The objectives, ambitions, and budget are also prerequisites for atlas design and its user interface.

2. Richard Smith and Thomas Parker discuss authoring tools in "An Electronic Atlas Authoring System" on pages 35-39 in this issue of Cartographic Perspectives. 
CONCLUDING REMARKS

\section{REFERENCES}

to make a production portable to all three platforms and their dialects is not recommended. Macintosh has nice tools, but in my opinion a DOS/ WINDOWS machine gives more flexibility, which may be needed to reach the objectives. The UNIX work station is for the very high end, professional user, who probably also uses the system for commercial production.

Once the platform has been chosen, the recommendation is to use standard tools for the cartographic presentation. At present, there is no need to do all the programming by yourself. However, the PC-Atlas of Sweden is a successful exception to this rule (Arnberg 1993).

Although the electronic atlas will not replace the book form, it can complement printed atlases. With modern information technology electronic atlas production is rather easy today. There is also a great demand from the schools for electronic teaching materials. The PC-Atlas of Sweden, for example, sells well to high schools and secondary schools. The distribution of electronic atlases is growing at an exponential rate, and it will not take long until electronic atlases are readily available on the Internet. ${ }^{3}$ Entrepreneurs in this field have great possibilities.

Aranaz del Rio, Fernando. 1993. Electronic Atlas Project for the National Atlas of Spain - Update Report. Proceedings of the ICA Seminar on Electronic Atlases. pp. 97-98. Visegrád, Hungary: Eötvös Loránd University.

Arnberg, Wolter. 1993. Design Concepts of the National PC-Atlas of Sweden. Proceedings from the ICA Seminar on Electronic Atlases. pp. 113128. Visegrád, Hungary: Eötvös Loránd University.

Bakker, Nico, Corné van Elzakker, and Ferjan Ormeling. 1988. Een Nationale-Atlas Informatiesysteem. Kartografisch Tidjschrift. 14.2: 43-52.

Köbben, Barend. 1993. Teaching Multimedia Production Techniques. Proceedings of the ICA Seminar on Electronic Atlases. pp. 79-88. Visegrád, Hungary: Eötvös Loránd University.

Massey, Jack. 1987. Space-Time charts path to success with CD-ROM. Computers and High Technology. The Australian. Tuesday March 31, 198733.

Monmonier, Mark. 1992. Authoring Graphic Scripts: Experiences and Principles. Cartography and Geographic Information Systems. 19.4: 247-260, 272.

Ormeling, Ferjan and Olev Koop. 1992. The Transition of a Paper National Atlas to a National Atlas Information System. Proceedings of the ICA National Atlas Commission Meeting. Bejing: China Cartographic Publishing House.

\footnotetext{
3. For example, since the time that this paper was presented Geomatics Canada now provides National Atlas Information Service on the World Wide Web-server: http://wwwnais.ccm.emr.ca.
} 
Rystedt, Bengt. 1987. The New National Atlas of Sweden. Professional Papers, LMV-Rapport 1987:17. National Land Survey, Gävle, Sweden.

Siekierska, Eva. 1983. Towards an Electronic Atlas. Proceedings of the AutoCarto VI, Reprinted in Cartographica, 21.2 \& 3, 1984, pp. 110-120.

Siekierska, Eva. 1993. From the Electronic Atlas System to the Electronic Atlas Products. Proceedings of the ICA Seminar on Electronic Atlases, pp. 103-111. Visegrád, Hungary: Eötvös Loránd University.

Smith, Richard. 1987. Electronic Atlas of Arkansas: Design and Operational Considerations. Proceedings of the 13th International Cartographic Conference, Vol IV, pp. 159-167. Aguascalientes, Mexico: Instituto Nacional de Estadistica, Geografia e Informatica.

Los atlas electrónicos tienen el potencial de añadir una nueva dimensión para el uso de la información de atlas. Una versión electrónica puede contener información y software para producir mapas que no serían posibles en el formato de libro. Pueden servir como paso preliminar para el Sistema de Información de Atlas y también pueden formar el núcleo para un sistema de información avanzada. La Comisión del ICA para atlas nacionales fue formada en la decimotercera Conferencia Cartográfica en Morelia, México en 1987 para servir como forum para la producción y concepción de atlas electrónicos. Las observaciones presentadas en este trabajo son resultados de estas reuniones.

Les atlas électroniques ont le potentiel d'ajouter une nouvelle dimension à l'utilisation de l'information fournie par les atlas. Une version électronique peut contenir les données et le logiciel nécessaires à la production de cartes impossibles à réaliser sous forme livresque ; elle pourrait servir d'étape préliminaire à des systèmes d'information sur les atlas et former le noyau d'un système multimédiatique. La commission ICA (Conférence cartographique internationale) sur les atlas nationaux a été formée à Morelia (Mexique) en 1987, à l'occasion de la 13è Conférence cartographique internationale, pour servir de forum à la conception et à la production d'atlas électroniques. Le sujet des atlas électroniques a été débattu depuis lors à toutes les réunions de la commission. Les observations présentées dans le présent document relèvent de ces réunions. 